\title{
RESEARCH
}

Open Access

\section{Spatial distribution pattern of taxonomic and phylogenetic diversity of woody flora in Andaman and Nicobar Islands, India}

\author{
K. N. Ganeshaiah" ${ }^{*}$, M. Sanjappa ${ }^{2}$, Raviprasad Rao ${ }^{3}$, C. Murugan ${ }^{4}$ and K. N. Shivaprakash ${ }^{5,6}$
}

\begin{abstract}
Background: The insular nature and unique geographical set up of Andaman and Nicobar Islands has led to the evolution of variety of rare and distinct flora with high endemism. Despite several efforts to document the floristic richness of the islands, there are no efforts to understand the spatial patterns in the taxonomic and phylogenetic diversity, and thence to arrive at the biogeographic origin and evolutionary history of the vegetation of this Island archipelago.
\end{abstract}

Methods: We used a fine scale spatial distribution and abundance data of woody plants documented from 841 grids along with their phylogenetic data and estimated metrics of taxonomic and phylogenetic similarity to identify taxonomically and phylogenetically distinct woody plant 'phytoregions' within Andaman and Nicobar Islands. We then arrived at the spatial patterns of the taxonomic richness and diversity and, of phylogenetic diversity across the entire Archipelago.

Results: We found that taxonomic richness and diversity of woody flora is high in Andaman and low in Nicobar Islands, whereas Nicobar Islands have a more phylogenetically diverse woody flora compared to Andaman. We identified three distinct woody plant 'phytoregions' within Andaman and Nicobar Islands. The three identified 'phytoregions' broadly match with the geographically isolated Island groups such as Andaman, Car Nicobar and Great Nicobar Islands; these 'phytoregions' also highlight the existence of two broadly distinct biogeographic zones of woody plants within the Islands.

Conclusion: Our analysis provides new insights into the spatial patterns of diversity of woody flora in Andaman and Nicobar Islands. We show that (i) both taxonomic and evolutionary affinities identify distinct 'phytoregions' closely segregated across the geographic distribution of the major islands of the archipelago, and (ii) there are two distinct biogeographic zones, i.e. Andaman flora most closely allied with flora of South western Burma and Nicobar more related with the flora of Malayan peninsula and Sumatra.

Keywords: Biogeographic zones, Phytoregions, Cluster analysis, Evolutionary distinctiveness, Phylogenetic beta diversity, Andaman and Nicobar Islands, Woody flora

\footnotetext{
* Correspondence: knganeshaiah@gmail.com

'School of Ecology and Conservation, University of Agricultural Sciences,

Bengaluru 560065, India

Full list of author information is available at the end of the article
} 


\section{Background}

The Andaman and Nicobar Islands are the string of oceanic Islands stretching from southwestern Burma to northwestern Sumatra, traditionally treated as an insular subdivision of the Indian Subregion (Oates and Blanford 1889-1898; Ali and Ripley 1968-1974; Champion and Seth 1968; Mani 1974). Geologically, the Andaman and Nicobar Island chain is believed to have been originated during Tertiary, when Indian plate collided with the southern edge of Asia and that the Andamanese/Nicobarese chain is part of the physical boundary, of Tertiary age, separating the ancient Gondwanan India from southeast Asia (Ali and Ripley 1983). The insular nature, unique geographical set up and physical Isolation between Islands have contributed to the evolution of rich biological diversity in the region, with a variety of rare and unique flora that are highly endemic to the region (Nayar 1996).

The Island region is well surveyed for both flora (Kurz 1870; Parkinson 1923; Thothathri 1965; Lal 1990; Elkunchwar et al. 1997; Padalia et al. 2004; Tripathi et al. 1994; Rajkumar and Parthasarathy 2008) and fauna (Ball 1873; Abdulali 1981; Abdulali and Grubh 1970; Tikader 1984), but with little attention to unravel the biogeographic and evolutionary history of the biota (Ripley and Beehler 1989). The geographical proximity of Andaman Islands to Myanmar and of Nicobar Islands to Sumatra and Indonesia, have prompted some biogeographers to believe that the biotic assemblages of Islands bears close affinities with those of the respective mainlands (Mani 1974; Balakrishnan and Ellis 1996). In other words, it is believed that biota of Andaman is derived from Myanmar and that of Nicobar Islands from Indonesia and Sumatra (Mani 1974; Balakrishnan and Ellis 1996). However, this view has been contested by some (Ripley and Beehler 1989) and such disagreement may stem from the differences in the taxonomic group that a specific study relies on. For example, the biogeographic studies are mostly based on bird distribution. But birds are highly migratory and can easily cross the oceanic barriers rendering them less ideal system to arrive at the biogeographic affinities. Clearly resolving the biogeographic patterns and affinities of Andaman and Nicobar Islands requires data from a vast set of species and a fine scale data on their distribution. In this paper we present the results of one such study on plants.

Floristically, Andaman and Nicobar Islands are among the most diverse regions within Indian subcontinent and in Indo-Burma and Sundaland biodiversity hotspot. There are over 2300 recorded vascular plant species (Arisdason and Lakshminarasimhan 2013) of which over 1400 are woody species (Kurz 1870; Parkinson 1923; Thothathri 1965). Woody plants, especially trees, represent one of the most distinguishing features of the vegetation in the region and they have been often used to describe the structure and composition of forest communities (Prasad et al. 2007; Padalia et al. 2004; Tripathi et al. 1994; Rajkumar and Parthasarathy 2008; Prasad et al. 2009). Within the Island region, woody plant richness is unevenly distributed, increasing from south to north, likely reflecting the seasonal variation in the rainfall (Ellis 1987). Locally however, woody plant richness is influenced by additional environmental variables such as forest type, topography and edaphic heterogeneity (Prasad et al. 2007; Prasad et al. 2009; Padalia and Roy 2010).

Most of floral studies of this area are restricted to a few patches of the archipelago; and there are hardly any efforts to map the spatial pattern of plant richness (Padalia et al. 2004; Tripathi et al. 1994; Prasad et al. 2007; Rajkumar and Parthasarathy 2008; Prasad et al. 2009). Owing to the sedentary nature, and difficulties of most plants to cross the vast saltwater barrier, the spatial distribution of woody plant across entire Island region can provide a valuable insight in to the biogeographic and biotic affinity of the Andaman and Nicobar Islands.

Phylogenetic analysis along with spatial distribution of taxa, serves as an effective tool to identify biogeographic groups in a region and thence to trace the evolutionary source of these groups (Graham and Fine 2008; Holt et al. 2012). In this paper, we have used fine scale spatial distribution and abundance data of woody plants documented from 841 grids $(3.125 \mathrm{~km} \times 3.125 \mathrm{~km})$ spread across entire Island region (Fig. 1) and phylogenetic hypotheses for recorded native woody plants (Additional file 1: Figure S1) to: 1) describe spatial pattern of richness, taxonomic and phylogenetic diversity 2) test whether there is significant variation in taxonomic composition and phylogenetic similarity of woody flora among Island regions and 3) test for the existence of distinct 'phytoregions' within Island region using taxonomic and phylogenetic similarity of native woody plants.

\section{Methods}

\section{Study area description}

The Andaman and Nicobar Islands are a group of 572 Oceanic Islands extending from $6^{\circ}$ to $14^{\circ}$ North latitudes and from $92^{\circ}$ to $94^{\circ}$ East longitudes. Situated in the junction of Bay of Bengal and Indian Ocean on one side and South China Sea and the Pacific Ocean on the other side, these Islands are part of an archipelago spread along $1120 \mathrm{~km}$ North to South. The major portion of this Archipelago constitutes five main islands, four in Andaman (North, South, Middle and Little Andaman) and one in the Nicobar (Great 


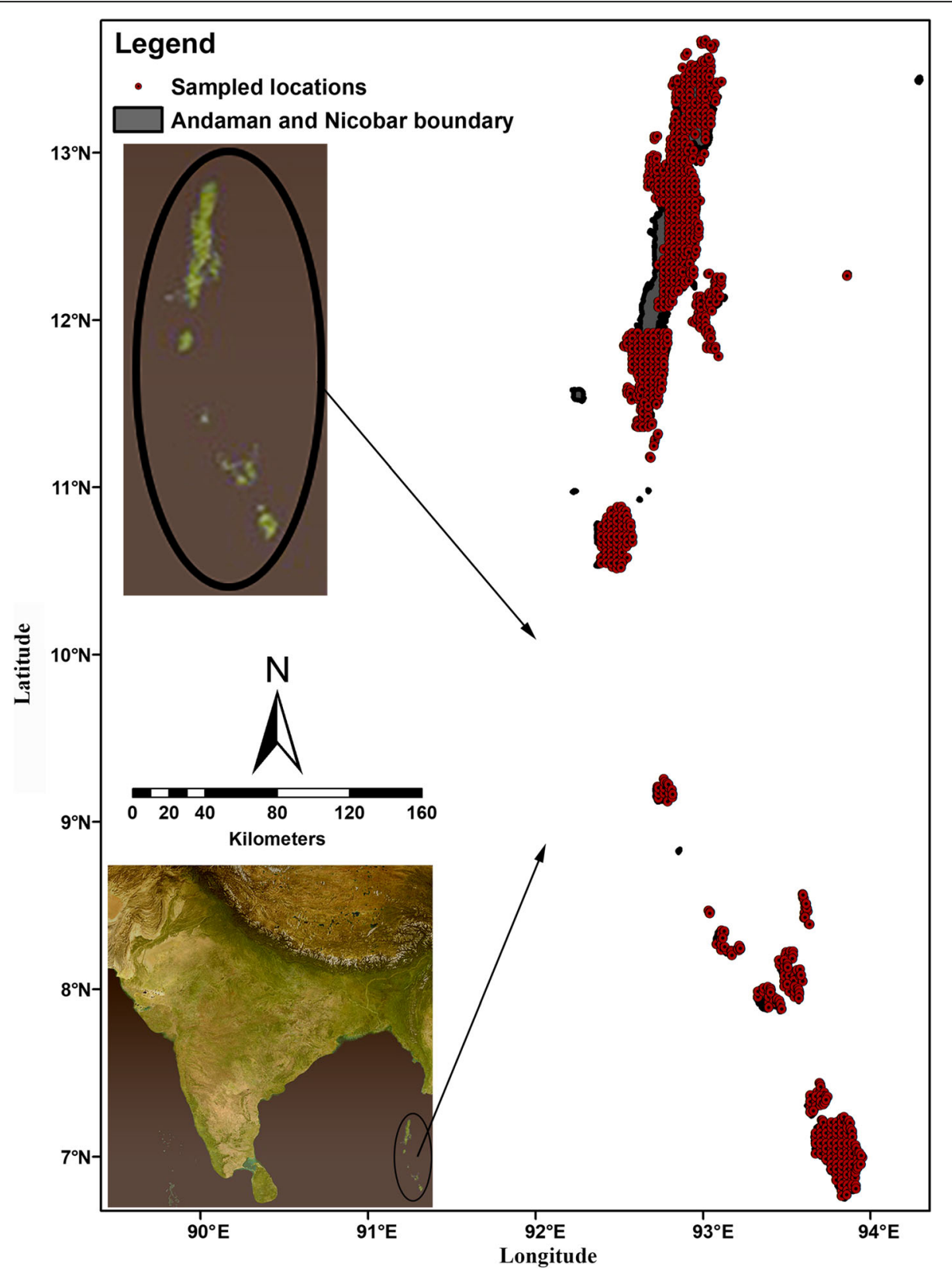

Fig. 1 Map of the study sites (Andaman and Nicobar Islands) showing the sampled locations of woody vegetation in the transects located in $3.125 \mathrm{~km} \times 3.125 \mathrm{~km}$ grid cells

Nicobar) covering a total area of $8239 \mathrm{~km}^{2}$. The northernmost Island (North Andaman) lies $285 \mathrm{~km}$ south west from mainland of Myanmar. At the southernmost point, great Nicobar lies $189 \mathrm{~km}$ northwest of the Sumatra coast. Further, a deep oceanic trench more than 1000 fathoms run between the Nicobar and Sumatra extending up to Narcondam.

Andaman and Nicobar Islands are among the major biodiversity eco-regions (Indo-Burma and Sundaland hotspot) in the world (Wikramanayake et al. 2002; Krupnick and Kress 2003). Like other archipelago, these tropical Islands are characterized by high endemicity and species diversity (Prasad et al. 2007). The Islands have a tropical humid climate with little seasonal variation in temperature (Mani 1974) and ranges from $21{ }^{\circ} \mathrm{C}$ (minimum in December) to $32^{\circ} \mathrm{C}$ (maximum in May). The islands receive rainfall from both south-west (SW) and north-east (NE) monsoon winds, the former is from May to September and the latter is from October to December with the average annual rainfall ranging from 300 to $3500 \mathrm{~mm}$ (Ellis 1987). The mean relative humidity is rather high and 
usually remains between $66 \%$ and $85 \%$ throughout the year. Topography is undulating, with hill ranges and narrow valleys. Soils are mostly acidic, poor in organic carbon and nitrogen (Devaraj 2001). According to Champion and Seth (1968), the vegetation of Andaman and Nicobar Islands is classified into six types: of these three are of evergreen types (Giant Andaman evergreen, Andaman Tropical Evergreen and Andaman hilltop evergreen) and others are Andaman moist deciduous forest, Semi-evergreen forest, Littoral forest and Mangrove forest.

\section{Woody vegetation sampling}

The entire Andaman and Nicobar archipelago was divided into 1042 grids of approximately $10 \mathrm{~km}^{2}(3.125$ $\mathrm{km} \times 3.125 \mathrm{~km})$ area. Among them, some grids falling in the urban area, well established settlements and plantations were discarded. Further, some of the grids in Jarawa tribal sanctuary could not be studied as the entry to this habitat is strictly restricted in order to protect this dwindling tribe from impending health problems that may arise due to contact with the outside world. Thus, a total of 841 grids were studied (Fig. 1). Belt transect(s) totaling a length of $1000 \mathrm{~m}$ (and $10 \mathrm{~m}$ wide) were laid in each of these 841 grids; the numbers (1-4) and the placement of the transects were decided on the basis of the spatial heterogeneity as observed from the NDVI value cumulated over a year (Ganeshaiah 2012). In each transect, all plants with $>10 \mathrm{~cm}$ DBH (diameter at breast height) were enumerated. Entire data was compiled into a database.

All specimens collected during the field studies were identified using local floras such as A Forest Flora of Andaman Islands (Parkinson 1923), Flora of Andaman and Nicobar Islands (Hajra et al. 1999), Flora of Great Nicobar Islands (Sinha et al. 1999), Flora Malesiana (http://portal.cybertaxonomy.org/ flora-malesiana/node/1) and a number of research papers published based on materials from these Islands. Further, the identifications were confirmed in consulting herbaria such as The Central National Herbarium (CNH) (CAL), Andaman and Nicobar regional center, PortBlair Herbarium (PBL) and virtual herbaria of Royal Botanic Gardens Kew (K) and Naturalis Biodiversity Center (National Herbarium Nederland) (L). We made 3-5 duplicates of all collections and sets are deposited in herbaria of CAL, PBL, Sri Krishnadevaraya University (SKU), Andhra Pradesh and University of Agricultural Sciences, Bengaluru (UASB). Although two of the co-authors (M Sanjappa and $C$ Murugan) have worked on the flora of these Islands and could identify majority of the species in the field, but every species mentioned is backed by voucher specimens. The herbarium acronyms given are as per "Index Herbariorum"- a international database maintained by the New York Botanical Garden, USA.

To further compare the taxonomic composition of woody flora from Islands with that of mainland Asia, we developed a woody species list of mainland Asian regions which possibly acted as a source species pool that bound Island regions: (1) Southern India/Sri Lanka, (2) Southwestern Burma, (3) the Malay Peninsula (inclusive of Malaysia, peninsular Burma and Southern Thailand), and (4) Sumatra (Additional file 1: Figure S2) (Ripley and Beehler 1989). These four source areas are roughly equivalent biogeographic entities, and thus useful for purposes of comparison (Graves \& Gotelli 1983). We complied species lists for these four source areas from multiple sources including published literature, online databases and floras (Additional file 1: Table S1). We also compared the taxonomic composition of woody flora within Island region, by dividing entire Island into eight different zones (each consisting of cluster of Islands) which consisted of six zones from Andaman Islands (two zones each from northern, middle and southern part of Andaman Islands) and two zones from Nicobar Islands (Additional file 1: Table S2). Then for each zone, we specifically developed species occurrence and abundance list for overall taxa as well as endemic taxa and did pairwise comparison of number of taxa shared between each Island zones (Additional file 1: Table S2).

\section{Generation of phylogenetic hypothesis}

We constructed a phylogeny for 696 woody plant species of Andaman and Nicobar Islands by adopting the following procedure: First, we grafted the species names of the 696 woody plants onto a backbone of the super tree published by Zanne et al. (2014) and matched the names. Among the 696 species, 301 (44\%) were present in Zanne et al. (2014) super tree. The remaining 395 (56\%) species were included in the phylogeny either as basal polytomies within the genus (Culmsee and Leuschner 2013; Hawkins et al. 2014) or placed randomly within the clade of their sister taxa by referring to molecular systematic literature (Brunbjerg et al. 2014). We used match.phylo.data function in PICANTE (Kembel et al. 2010) and drop.tip function in PHYTOOLS (Revell 2012) to match and prune the mega phylogeny of Zanne et al. (2014) to the focal species list of Andaman and Nicobar Islands. By following the above procedure, we generated 101 phylogenetic topologies for woody plant species of Andaman and Nicobar Islands, which includes one maximum clade credibility tree and 100 bootstrap set of time-scaled MLE trees obtained using mega phylogeny of Zanne et al. (2014) (http:// 
datadryad.org/resource/doi:10.5061/dryad.63q27.2/3.1). The phylogeny showing the relationships of 696 woody plant species of Andaman and Nicobar Islands is given in Additional file 1: Figure S1.

To account for phylogenetic and branch length uncertainties, all phylogenetic diversity and clustering analyses were repeated across the 101 phylogenetic trees.

\section{Computing taxonomic and phylogenetic diversity}

We first computed the basic taxonomic diversity measures such as species richness, Simpson and Shannon's diversity Index for each grid and for each Island zone. We also computed the following phylogenetic diversity metrics for each grid and for each Island zone.

Standardized effect size of phylogenetic diversity $\left(\mathrm{PD}_{\mathrm{SES}}\right)$ : We first calculated Faith's PD for each grid as the summed length of unique branches leading to species of the grid in the phylogeny excluding the root. Because PD is strongly correlated with species richness (Forest et al. 2007; Fritz and Rahbek 2012), we calculated deviation of PD from a global null expectation $\left(\mathrm{PD}_{\text {random }}\right)$ as the mean value of $\mathrm{PD}$ over 1,000 trees generated by randomly reshuffling the species at the tree tips (phylogeny pool null model). Then, we used the following formula to calculate the $\mathrm{PD}_{\mathrm{SES}}$.

$$
\mathrm{PD}_{\mathrm{SES}}=\left(\mathrm{PD}-\mathrm{PD}_{\text {random }}\right) / \mathrm{sd} \text { of } \mathrm{PD}_{\text {random }}
$$

Standardized effect size of mean pairwise phylogenetic distance $\left(\right.$ MPD $\left._{\text {SES }}\right)$ among species in each grid was calculated using following formula.

$$
\mathrm{MPD}_{\mathrm{SES}}=\left(\mathrm{MPD}-\mathrm{MPD}_{\text {random }}\right) / \mathrm{sd} \text { of } \mathrm{MPD}_{\text {random }}
$$

The null model used for both phylogenetic diversity measure was abundance weighed. The negative values of $\mathrm{PD}_{\mathrm{SES}}$ and $\mathrm{MPD}_{\mathrm{SES}}$ indicate phylogenetic clustering (lower than expected phylogenetic diversity) whereas positive values indicate overdispersion (higher than expected phylogenetic diversity). All taxonomic and phylogenetic diversity measures were calculated using following packages: APE (Paradis et al. 2004), PICANTE (Kembel et al. 2010), VEGAN (Oksanen et al. 2015) and PHYLOMEASURES (Tsirogiannis and Sandel 2016).

The taxonomic and phylogenetic diversity indices were mapped on to grids and processed using ArcMap 10.0 (ESRI (Environmental Systems Resource Institute) 2010).

\section{Beta diversity metrics and delineating clusters or floristic regions}

To delineate the taxonomically and phylogenetically distinct floristic regions, we conducted cluster analyses on pair-wise matrices of taxonomic and phylogenetic beta diversity (hereafter " $\beta$ " and " $p \beta$ "). Beta diversity $(\beta)$ represents the composition dissimilarity of species found between two communities (i.e. variation of the species composition of assemblages), which can be the outcome of two different phenomena: spatial species turnover and the nestedness of assemblages (Baselga 2010). On the other hand, phylobetadiversity $(\mathrm{p} \beta)$ represents the variation in the phylogenetic composition of assemblages, which is a measurement related to evolutionary time. $p \beta$ can also be partitioned into two components related to lineage turnover and the phylogenetic nestedness of assemblages (Leprieur et al. 2012). Therefore, the selection of the dissimilarity measure used to quantify the differences between assemblages (beta diversity $(\beta)$ ) can be crucial, because different dissimilarity indices account for the two phenomena in different ways.

Thus, following Baselga (2010) we used two dissimilarity measures Simpson index (sim) and Sørensen index (sor), which accounts for both turnover and nestedness components in calculation of beta diversity $(\beta)$. Hereafter, we refer $\beta$ sim and $\beta$ sor for taxonomic component of Simpson and Sørensen beta diversity and $p \beta s i m$ and $\mathrm{p} \beta$ sor for phylogenetic component of Simpson and Sørensen beta diversity. The $\beta$ sim metric is preferable to other beta diversity metrics because it is insensitive to differences in species richness among assemblages (Lennon et al. 2001), thus provide an unbiased estimation of compositional turnover among grid cells (Kreft and Jetz 2010). The Bsor metric is also preferable, because this metric is influenced by diversity gradients, which are very relevant to study the spatial pattern of diversity (Jønsson and Holt 2015). The phylogenetic beta diversity ( $\mathrm{p} \beta$ sim and $\mathrm{p} \beta$ sor) were calculated similar to taxonomic beta diversity ( $\beta$ sim and $\beta$ sor), where the proportion of shared phylogenetic branch lengths of the phylogenetic tree between cells are substituted for species (Graham and Fine 2008). Both $\beta$ sim and $\beta$ sor values range from 0 (when species composition is identical between grid cells), to a maximum value of 1 (when there are no shared taxa). Finally, we generated pairwise distance matrices of taxonomic ( $\beta$ sim and $\beta$ sor) phylogenetic beta diversity ( $\mathrm{p} \beta$ sim and $\mathrm{p} \beta$ sor) between all grid cells at the $3.125 \mathrm{~km} \times 3.125 \mathrm{~km}$ scale and subjected these beta diversity matrices to further cluster analyses.

In order to choose a best clustering algorithm, which can identify best number of spatial clusters or floristic regions, we performed eight hierarchical clustering algorithms on the $\beta$ sim, $\beta$ sor, $p \beta$ sim and $p \beta$ sor matrices: single linkage, complete linkage, unweighted pair-group method using arithmetic averages (UPGMA), unweighted pair-group method using centroids (UPGMC), weighted pair-group method using arithmetic averages (WPGMA), weighted pair-group method using centroids (WPGMC), Ward's minimum variance and DIANA's divisive hierarchical method. 
The validity of clustering results was evaluated using the cophenetic correlation coefficient (Sokal and Rohlf 1962), which defines the relationship between the terminals of a dendrogram with the original distance matrix for all cluster methods and has a value between 0 (poor correlation) and 1. High co-phenetic values indicate strong support for the placement of the cluster whereas low values indicate weak support. This therefore represents a direct measure of how much of the original information is retained in the dendrogram (Kreft and Jetz 2010).

Determining optimum number of clusters is always a challenging issue (Milligan and Cooper 1985; Heikinheimo et al. 2007; Escalante et al. 2013). Here, we used three different methods to determine optimum number of clusters and to identify distinct floristic regions: Elbow method, Average Silhouette method and Gap statistic method.

Finally, we delimited clusters (or floristic regions) using a scatter plot (cluster plot), non-metric multidimensional scaling (NMDS) ordination and hierarchical dendrogram of dissimilarity on the $\beta$ sim, $\beta$ sor, $p \beta$ sim and $\mathrm{p} \beta$ sor matrix. All analyses were conducted in $\mathrm{R}(\mathrm{R}$ Core Team 2013), using the R-libraries APE (Paradis et al. 2004), PICANTE ((Kembel et al. 2010), BETAPART (Baselga and Orme 2012), VEGAN (Oksanen et al. 2015), CLUSTER (Maechler et al. 2013) and NBCLUST (Charrad et al. 2014). Geographical data and maps were processed in ArcMap 10.0 (ESRI (Environmental Systems Resource Institute) 2010).

\section{Characterizing the cluster features}

We characterized the clusters based on their association with the ten most dominant and rare families. The ten dominant and ten rare families were chosen based on their frequency of occurrence in grid cells; the families present in more than $50 \%$ of grid cells were categorized as dominant and those present in $<15 \%$ of grid cells were categorized as rare families. Then, we computed the Chi-Square values as a surrogate of contribution of each family to the delimited clusters (floristic regions).

We also evaluated the differences in various taxonomic and phylogenetic diversity measures among delimited clusters or floristic regions based on $\mathrm{p} \beta$ sim using one-way ANOVA. TukeyHD test was used to determine if the mean difference in various taxonomic and phylogenetic diversity measures between specific pairs of delimited clusters (floristic regions) are statistically significant. The ANOVA test assumes that, the data are normally distributed and the variance across groups are homogeneous. We checked for normality of data and homogeneity of variance among clusters using residuals versus fits plot and Levene's test.

All statistical analyses were conducted using the following R packages: VEGAN (Oksanen et al. 2015), CAR
(Fox et al. 2012), CORRPLOT (Wei and Simko 2017) and VCD (Meyer et al. 2014).

\section{Results \\ The composition, endemism and affinities of island woody flora}

We recorded 696 woody plant species in Andaman and Nicobar Islands during our extensive field survey. Of which, 66 (9.5\%) taxa are endemic to the Island region. 58 $(86 \%)$ of 66 endemic taxa occur in Andaman, whereas only 28 (42\%) endemic taxa occur in Nicobar Island. Of the 66 endemic woody taxa, 38 (58\%) taxa exclusively occur in Andaman, 9 (14\%) taxa exclusively occur in Nicobar and 19 (29\%) taxa are shared between Islands. We found considerably high difference in woody flora shared between Andaman and Nicobar Islands (Additional file 1: Table S2). Only 163 of the 275 (59\%) species of Nicobarese woody plants also occur in Andaman. By comparison, the number of taxa shared was higher among zones within Island than among the zones in two different Island (Additional file 1: Table S2). The zones (Nicobar 1 and 2) in Nicobar Island shared only $35 \%$ to $56 \%$ of their woody flora with six Island zones in Andaman (Additional file 1: Table S2). Further, the Island zones in Andaman had higher species richness than Island zones in Nicobar (Additional file 1: Table S2). However, the endemic species richness did not differ much among Island zones (Additional file 1: Table S2).

Further, to test our hypothesis that the Andaman and Nicobar constitute a phytogeographically different unit of woody flora, we compared the relationship of woody flora from the two islands to the four postulated source regions (Additional file 1: Figure S2). A Chi-square test comparing the relative affinities of woody flora from these two islands with those of south-western Burma, Sumatra, South India and Malayan peninsula, showed us relatively significant difference $\left(\mathrm{df}=3, \chi^{2}=6.444, P>\right.$ 0.092), indicating the Andamanese and Nicobarese woody flora are subsets of a different phytogeographic unit. Of the 584 woody taxa recorded in Andaman Island, 375 species (64\%) also occur in South western Burma, while the other source areas share between $43 \%$ to $51 \%$ of the island woody flora (Additional file 1: Figure S2). In comparison, of the 275 woody taxa recorded in Nicobar, 185 species (65\%) occur in Malayan peninsula, 165 species (58\%) are shared with Sumatra, while the other source areas share between $40 \%$ to $53 \%$ of island woody flora (Additional file 1: Figure S2). Then, the woody flora of Andaman Island is most closely allied with source woody flora of South western Burma and Nicobarese woody flora is most closely allied with source woody flora of Malayan peninsula and Sumatra (Additional file 1: Figure S2). 
A number of studies have stated that the biota of the Andaman and Nicobar Islands substantially differ from each other (Elwes 1873; Ball 1873; Wallace 1876; Blanford 1901; Mani 1974). This pattern is highly evident for the island woody flora (Additional file 1: Figure S2).

\section{Spatial pattern of taxonomic and phylogenetic diversity of woody flora in islands}

The spatial distribution pattern of woody plant richness at all taxonomic levels (family, genus and species) did not show the expected trend of increasing richness from north towards equator. In fact, the Andaman Islands in the north, especially the mid part of Andaman area $\left(12^{\circ}\right.$ to $\left.13^{\circ} \mathrm{N}\right)$ showed high diversity of families, genera and species (Fig. 2a to c); Lowest richness at all these taxonomic levels was seen at and around the Car-Nicobar Islands $\left(8^{\circ}\right.$ to $\left.11^{\circ} \mathrm{N}\right)$. The great Nicobar island group at the southernmost tip $\left(6^{\circ}\right.$ to $\left.7.5^{\circ} \mathrm{N}\right)$ also showed a few patches of relatively high taxonomic richness (Fig. 2a to c). This disjunct pattern of richness at the north and south was more evident with the taxonomic diversity estimates. The Shannon and Simpson taxonomic diversity indices showed high diversity in the entire Andaman Islands in the north $\left(10^{\circ}\right.$ to $\left.14^{\circ} \mathrm{N}\right)$ and in the Nicobar Islands in the south $\left(6^{\circ}\right.$ to $\left.7.5^{\circ} \mathrm{N}\right)$, but poor diversity in the middle of Archipelago $\left(8^{\circ}\right.$ to $11^{\circ} \mathrm{N}$, Fig. 3a and b). This pattern was also reflected in the phylogenetic diversity, though southern part of the archipelago was phylogenetically more diverse (Fig. $3 \mathrm{c}$ and $\mathrm{d}$ ) from $6.58^{\circ}$ to $9^{\circ} \mathrm{N}$. The taxonomic and phylogenetic similarity of the woody flora however, showed decreasing trend from south to north (Figs. 4a to b). The woody flora in Andaman Islands were both taxonomically and phylogenetically distinct (less similar) compare to woody flora in Nicobar Islands (Fig. 4a to b) (see
Additional file 1: Figure. S5C to S5D for the comparable distribution of phylogenetic similarity of woody flora across geographic space of Andaman and Nicobar Islands using Sorenson dissimilarity index). Among eight zones in Bay Island, the two zones (Nicobar 1 and 2) in Nicobar had lower species richness and taxonomic diversity compare to six Island zones in Andaman (Additional file 1: Table S3). The phylogenetic diversity showed contrasting trend to that of taxonomic diversity (Additional file 1: Table S3). The Island zones in North Andaman and Nicobar had higher phylogenetic diversity compared to Island zones in middle and south Andaman (Additional file 1: Table S3).

Of the eight alternative clustering algorithms, UPGMA (unweighted pair-group method using arithmetic averages) was chosen as the best clustering algorithm to delineate clusters or floristic regions using original distance matrix of both taxonomic ( $\beta$ sim and $\beta$ sor) and phylogenetic ( $\mathrm{p} \beta$ sim and $\mathrm{p} \beta$ sor $)$ beta diversity $((\beta$ sim and $\beta$ sor: cophenetic $r=0.775$ and 0.700$)$, (p $\beta$ sim and $\mathrm{p} \beta$ sor: cophenetic $r=0.689$ and 0.750); Additional file 1: Table S4). The 'Elbow' method and 'Average Silhouette' method identified 3 optimal clusters for $\beta$ sim and $\beta$ sor and 3 and 2 optimal clusters respectively for $\mathrm{p} \beta$ sim and $\mathrm{p} \beta$ sor (see Additional file 1: Figures S3 to S5). They were used to delineate taxonomically and phylogenetically distinct floral regions in Andaman and Nicobar Islands.

The phylogenetic clustering using Simpson Dissimilarity index thus indicated three distinct vegetation groups that showed a clear spatial segregation across the archipelago (Fig. 5b). Vegetation type of cluster 1 that occurred in 466 grids $\left(4713 \mathrm{~km}^{2}\right)$ was distributed mostly in the Andaman group in the north $\left(10^{\circ}\right.$ to $\left.14^{\circ} \mathrm{N}\right)$, while that associated with cluster 3 was distinctly restricted to 160 grids $\left(1617 \mathrm{~km}^{2}\right)$ in the Nicobar group in the south
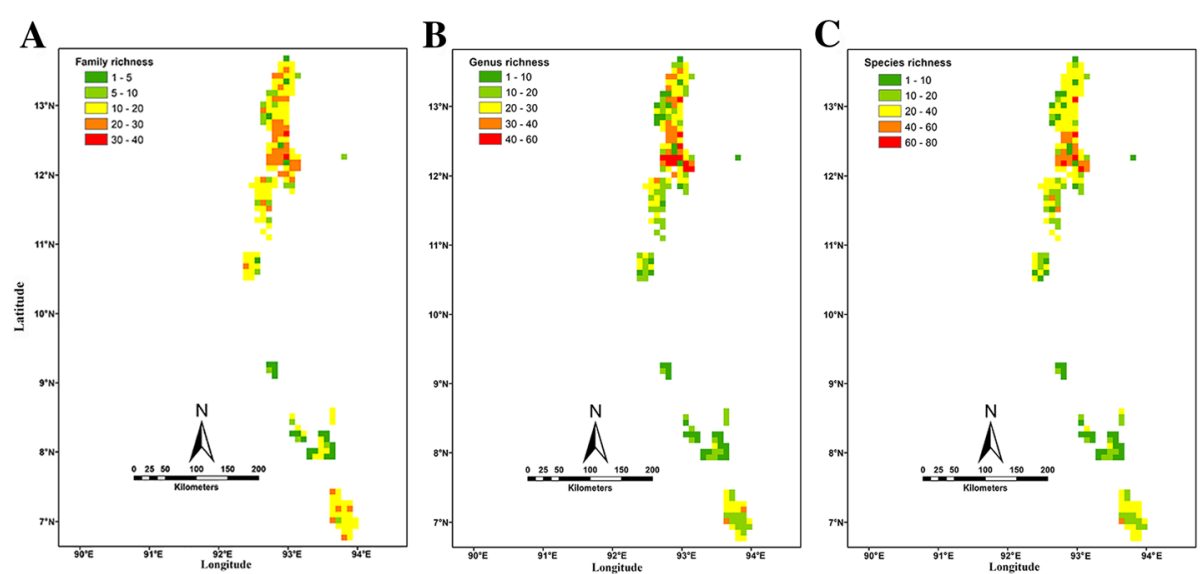

Fig. 2 Map showing the woody vegetation richness pattern across different taxonomic level per transect in the Andaman and Nicobar Islands. a Family richness, b Genus richness, c Species richness 

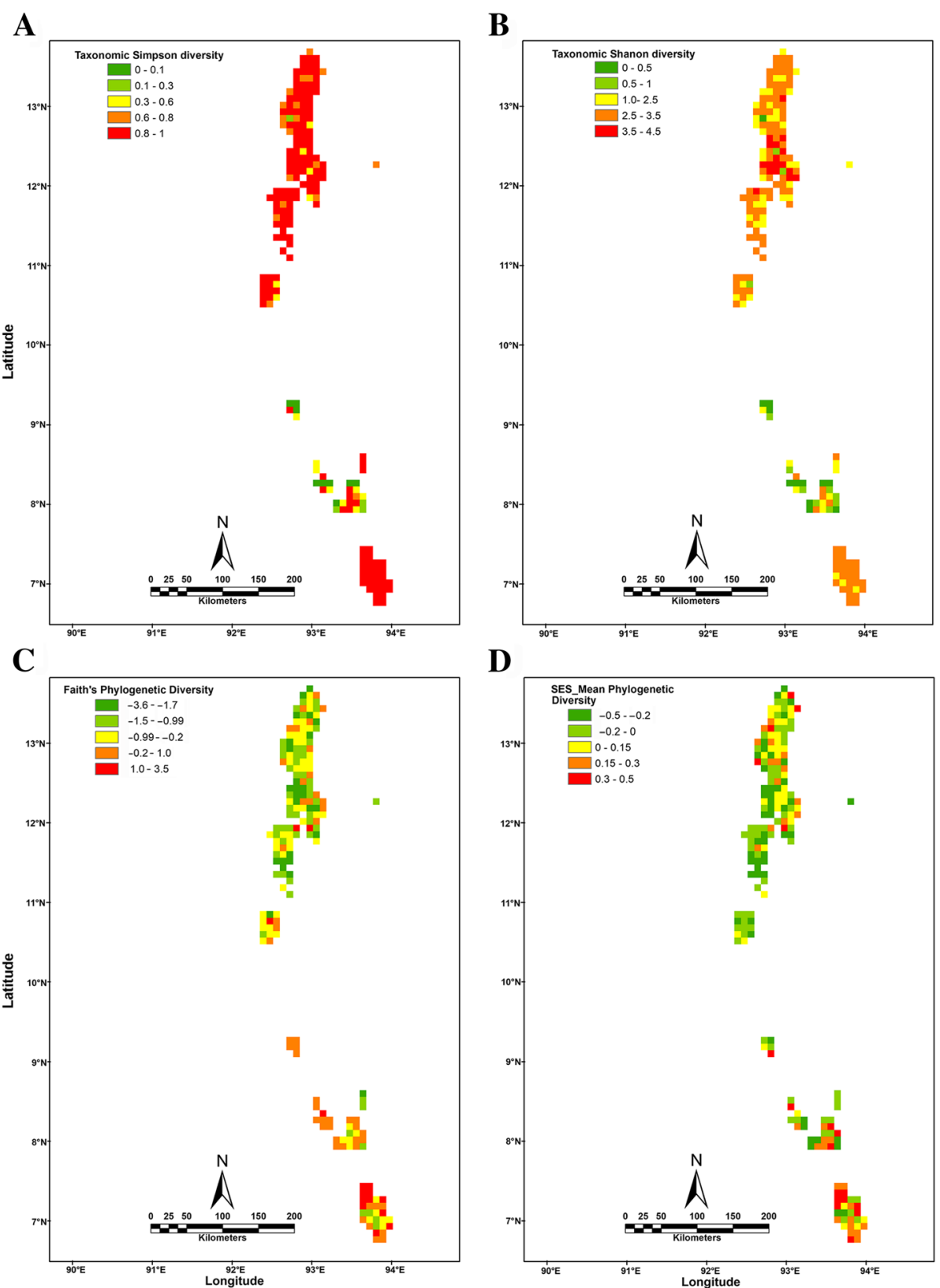

Fig. 3 Map showing the taxonomic and phylogenetic diversity pattern of woody vegetation per transect in the Andaman and Nicobar Islands. a Taxonomic Simpson diversity, b Shannon diversity index, c Faith's phylogenetic diversity and $\mathbf{d}$ Mean phylogenetic diversity (MPD)

$\left(6.5^{\circ}\right.$ to $\left.8^{\circ} \mathrm{N}\right)$ in; vegetation type of cluster 2 occurring in 180 grids $\left(1820 \mathrm{~km}^{2}\right)$ was spread out in the islands between these two major areas in the central part of the archipelago (Fig. 5b). Taxonomic clusters also reflected a similar but not so spatially distinct separation; vegetation of Andaman Islands in the north appears distinct from that of Nicabar islands in the south, though the boundaries were not so clear as in phylogenetic clustering (Fig. 5a) (see Additional file 1: Figures S6A to S6B for the comparable distribution of clusters using Sorenson dissimilarity index).
We further explored taxonomic and phylogenetic relationships among woody flora of Andaman and Nicobar Islands using NMDS ordination (Fig. 5c and f) and a hierarchical dendrogram (Additional file 1: Fig. $5 \mathrm{~b}$ and e). The NMDS ordination indicates clear separation between cluster 1 and cluster 3 for phylogenetic clusters (Fig. 5f), whereas the separation among three clusters were not clear for taxonomic clusters (Fig. 5c). Similarly, hierarchical dendrogram indicates clear separation between cluster 1 and cluster 3 for phylogenetic clusters (Fig. 5e), whereas clear 

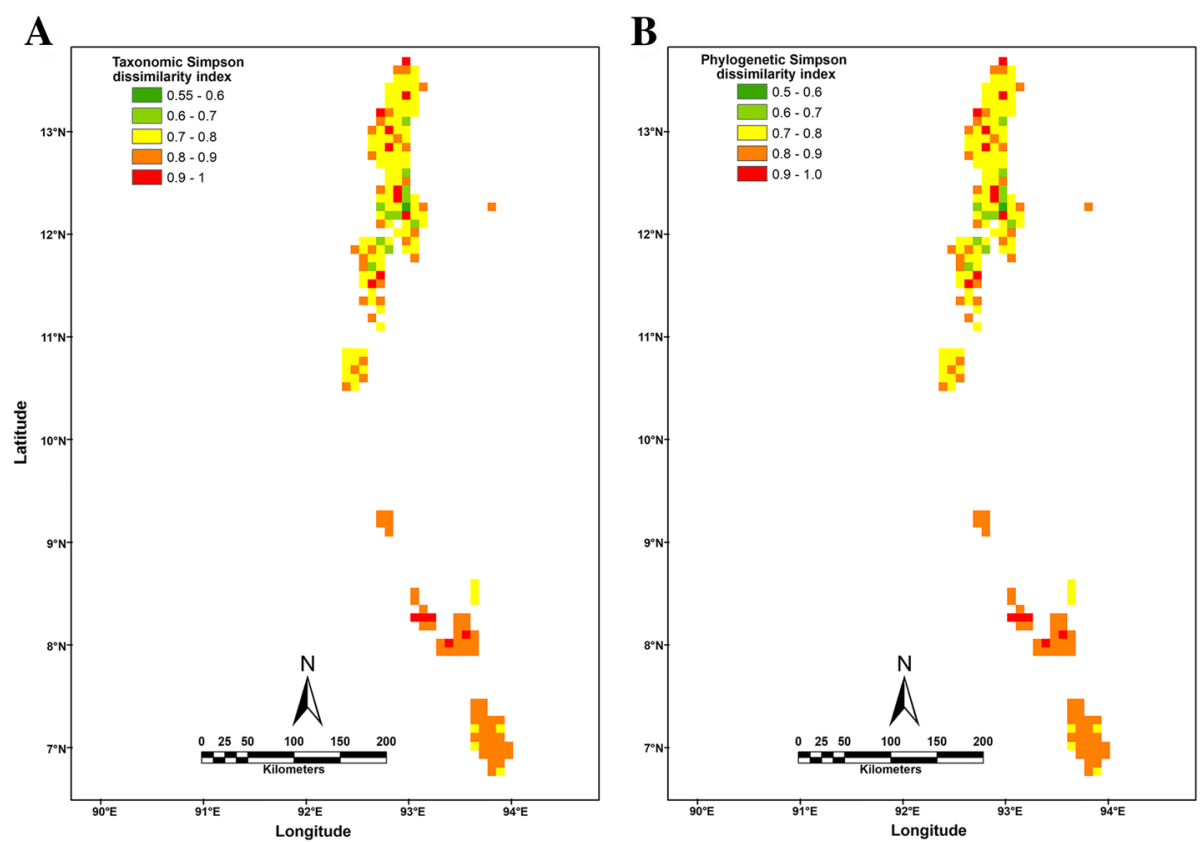

Fig. 4 Map showing the taxonomic and phylogenetic similarity of woody flora in Andaman and Nicobar Islands. a Taxonomic Simpson dissimilarity index and $\mathbf{b}$ Phylogenetic Simpson dissimilarity index

separation among all three clusters (cluster 1, 2 and 3) for taxonomic clusters (Fig. 5b).

We then characterized the features of these clusters on the basis of their taxonomic richness, taxonomic and phylogenetic diversity and family composition:

a) Richness, taxonomic and phylogenetic diversity: We also investigated difference in taxonomic and phylogenetic diversity among three delimited phylogenetic clusters and found that both taxonomic and phylogenetic diversity measures differed significantly among all three phylogenetic clusters (Additional file 1: Table S5 and Additional file 1: Figures S7A to S7F). Mainly, cluster 2 had significantly higher species richness and taxonomic diversity compare to other clusters (cluster 1 and 3) (Additional file 1: Figures S7A to S7C), whereas cluster 3 had significantly higher phylogenetic diversity compare to cluster 1 and cluster 2 (Additional file 1: Figures S7E to S7F).

b) Family composition: Among the ten dominant families: Meliaceae contributed significantly to all three clusters by representing $52 \%$ to $55 \%$ of total species and Fabaceae and Myristicaceae contributed only to cluster 3 by representing 18\% to $71 \%$ of total species in the family (Additional file 1: Figs. 6a to $\mathrm{b}$ and Additional file 1: Table S6). Whereas among rare families, Gentianaceae contributed the most to cluster 3 followed by Lauraceae, Melastomataceae Putranjivaceae, Nyctaginaceae and
Asparagaceae by representing 0 to $100 \%$ of total species present in the families and only Gentianaceae and Nyctaginaceae contributed to the cluster 2 by representing $33.3 \%$ to $100 \%$ of total species present in the families respectively (Additional file 1: Fig. 6c to d and Additional file 1: Table S6) (also see Additional file 1: Figures S8 to S10 for the comparable contribution of dominant and rare families to taxonomic and phylogenetic clusters using Sorenson dissimilarity index)

\section{Discussion}

We used fine scale spatial distribution and abundance data of woody plant species from 841 grids $(3.125 \mathrm{~km} \times 3.125$ $\mathrm{km})$ and their phylogenetic relatedness to unravel the spatial pattern of taxonomic and phylogenetic diversity of woody flora in Andaman and Nicobar Islands, a $550 \mathrm{~km}$ long archipelago well known for its rich, unique and diverse flora (Kurz 1870; Parkinson 1923; Thothathri 1965).

We found contrasting patterns for richness, taxonomic and phylogenetic diversity of woody flora in Andaman and Nicobar Islands. The Andaman Islands had higher family, genus and species richness and high taxonomic diversity of woody flora compare to Nicobar Islands. We observed opposite trend for phylogenetic diversity, with Nicobar Islands having a higher phylogenetic diversity compared to Andaman Islands. The expected latitudinal pattern of increasing diversity along North-South gradient, (now shown by several workers in several taxa) is surprisingly not seen in Andaman and Nicobar Islands (Cook 


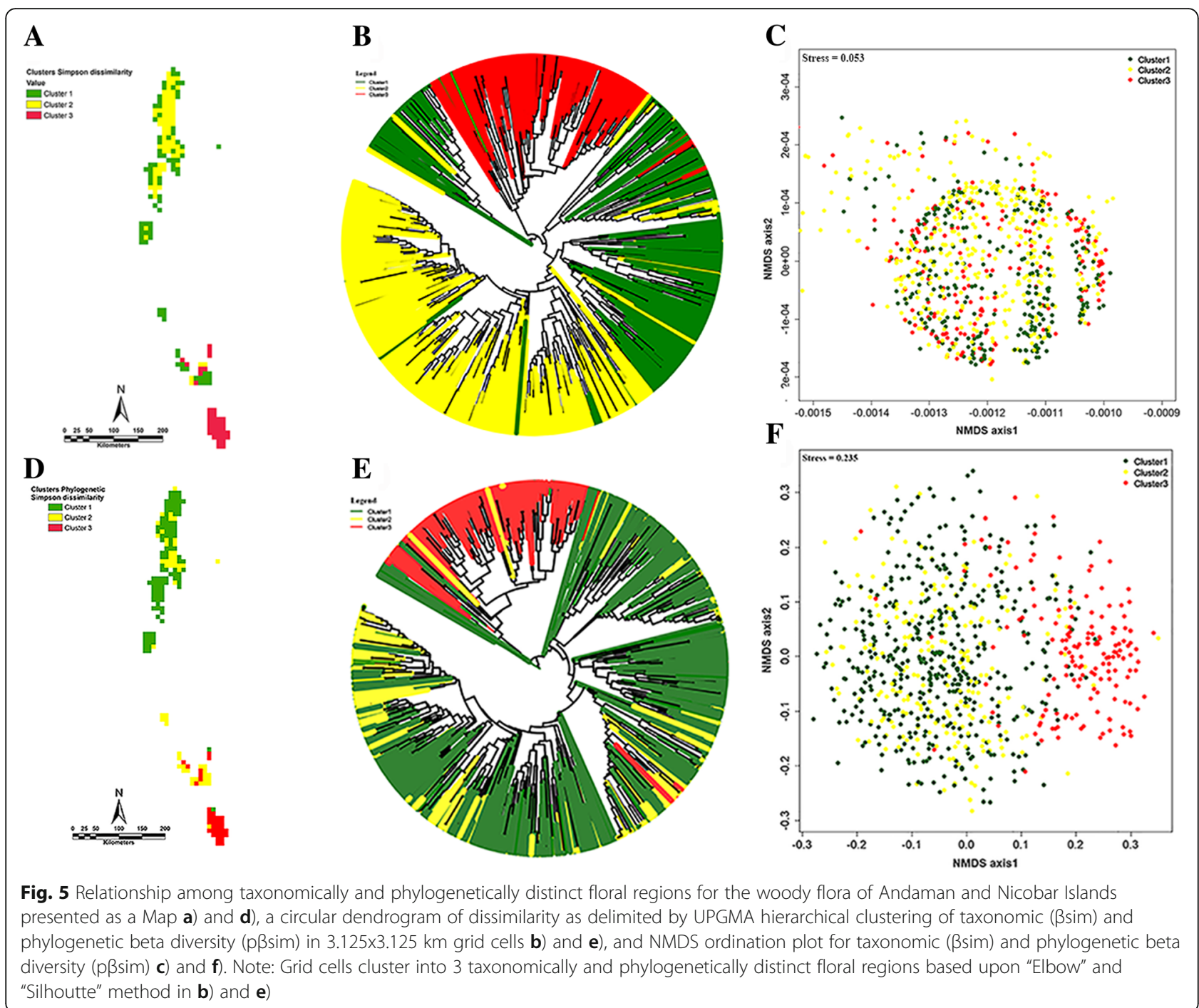

1969; Owen and Owen 1974; Santelices 1980; Cushman et al. 1993; Pyron and Burbrink 2009; Rivadeneira et al. 2011; Valdovinos et al. 2003; Abrahamczyk et al. 2014; Duchêne and Cardillo 2015; Morinière et al. 2016). Rather the diversity showed a disjunct pattern of high richness in the north (Andaman Islands) and in the south (Nicobar Islands) but with poor diversity in central part of archipelago. There could be two reasons for this spatial pattern:

1) Unusual distribution of climatic variables in the archipelago: For example, the Andaman Islands on an average receive high rainfall and show little variation in precipitation seasonality compared to Nicobar Islands (Ellis 1987). However, our results also suggest that, many climatic variables related to precipitation show increasing trend from North to South showing peak in mid latitude at $12^{\circ}$ to $12.5^{\circ}$ $\mathrm{N}$, whereas temperature shows weak decreasing trend (results not shown). Thus, the climatic variables can only partly explain the disjunct and contrasting spatial pattern of richness and diversity. Though, multiple studies from tropical region have shown that, species richness, taxonomic and phylogenetic diversity patterns are strongly correlated with climatic variables such as precipitation, temperature etc. (Ramesh et al. 2010; Joseph et al. 2012; González-Caro et al. 2014), we did not find such effect of climatic variables in shaping the diversity pattern in Andaman and Nicobar woody flora.

2) Different vegetation assemblages along archipelago: We found that the vegetation of the North and South constitute two separate assemblages with the central part of the Archipelago having an intermediate type between these two (Fig. 5). Such diverse vegetation composition could have disturbed the expected latitudinal gradient of diversity. In support of this, there was a clear 

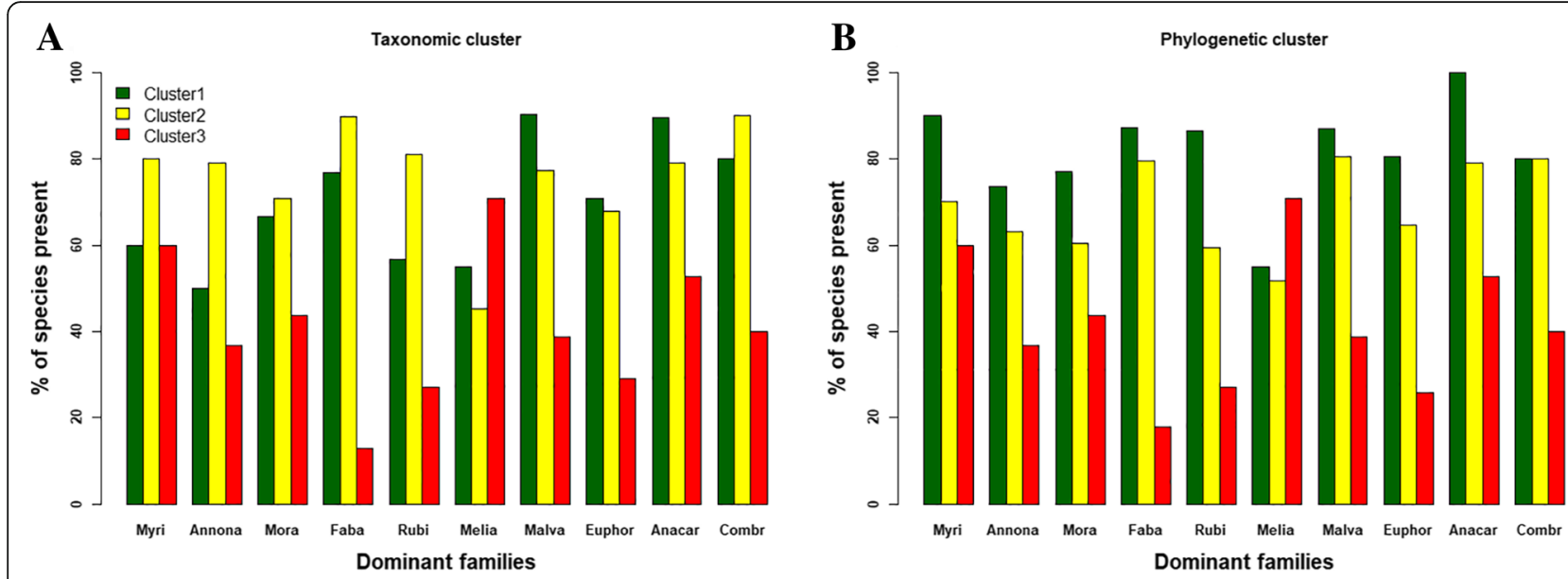

C

D
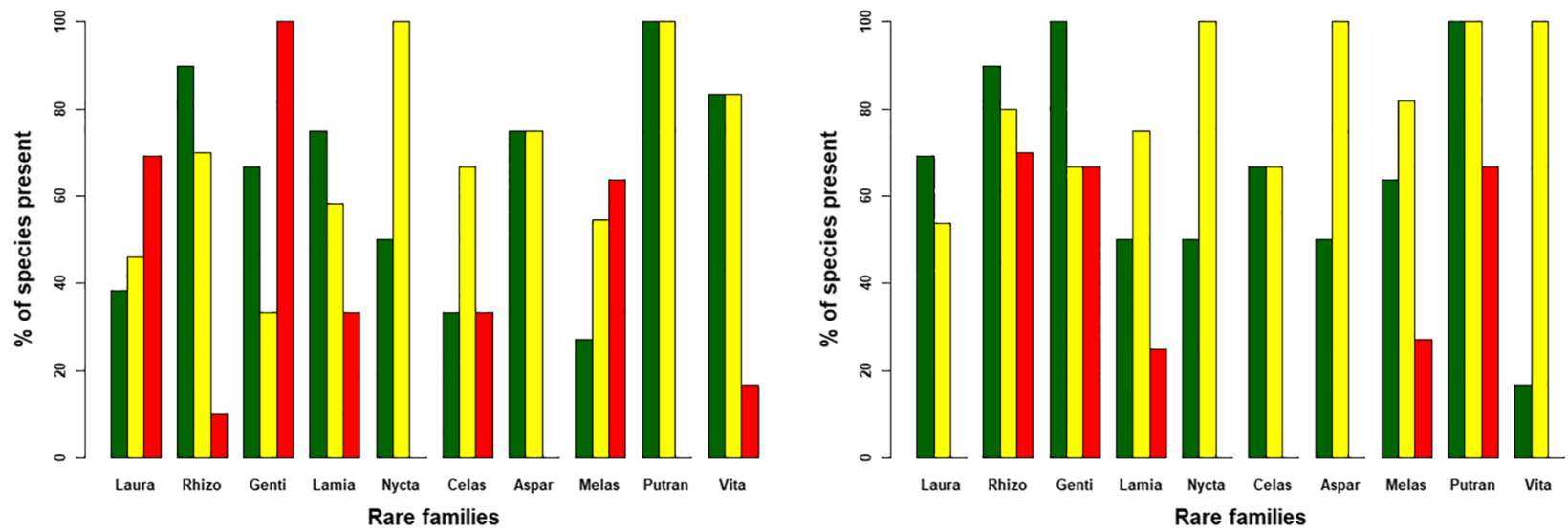

Fig. 6 Bargraph showing contribution of ten dominant and rare families to each of the three taxonomic and phylogenetically distinct cluster as delimited by UPGMA hierarchical clustering of taxonomic and phylogenetic beta diversity (p $\beta \operatorname{sim}$ ) in $3.18 \mathrm{~km} \times 3.18 \mathrm{~km}$ grid cells in Andaman and Nicobar Islands: $\mathbf{a}$ and $\mathbf{c}$ contribution of dominant and rare families to taxonomic cluster; $\mathbf{b}$ and $\mathbf{d}$ contribution of dominant and rare families to phylogenetic cluster

difference in the richness and diversity of these clusters (see Additional file 1: Figure S7). Further, the observed pattern of richness and diversity (taxonomic and phylogenetic) of woody flora among Andaman and Nicobar Islands might also be explained by other factors such as habitat heterogeneity (Murali et al. 2003), area of the Islands (Diamond 1970; Mayr and Diamond 1976; Heaney 1986), historical biogeography of flora (Ricklefs and Schluter 1993; Ricklefs 2004) and speciation and extinction processes (Hubbell and Foster 1986). However, future studies incorporating these factors may further reveal their importance on spatial assembly and diversity pattern of flora in Andaman and Nicobar Islands.

The three identified Phyto-regions are spatially segregated and match with three major geographically separated island clusters such as Andaman (North), Car
Nicobar (central part) and Great Nicobar Islands (South). While two major clusters occupied the extreme parts of archipelago, Cluster 1 in North (Andamans) and Cluster 3 in the South (Nicobar) and Cluster 2 which seems to be composed of the species from the major clusters occupying the mid zone of archipelago and hence could represent a confluence of the two Phyto regions from either end of the archipelago. The comparison of woody flora of Island and four possible mainland source regions support the affinity of Andamanese woody flora with south-western Burma and affinity of Nicobarese woody flora with Malayan peninsula and Sumatra. Results suggest that the woody flora colonized island regions at least from two main route- south-western Burma and Malayan peninsula. The Island woody flora that occur in two main possible source regions include 425 (61\%) species for Burma, 369 (53\%) species for Malayan peninsula, 321 (46\%) species for south India, and 311 species (44.7\%) for Sumatra. The 
importance of different source regions to colonization of woody flora in Andaman and Nicobar islands is also supported by distinct taxonomic composition of these islands. Only 163 of the 275 (59\%) Nicobarese woody species also occur in Andaman. The importance of Burma, Malayan peninsula and Sumatra for colonization of woody flora in different parts of Bay Island such as Andaman and Nicobar are supported by their higher affinity of woody flora with respective Island regions. Andaman shared their higher number of taxa (64\%) with south-western Burma and Nicobar shared their higher number of woody taxa with Malayan peninsula (65\%) followed by Sumatra (58\%). Thus, it appears possible that the flora of North part (Andamans) is derived from Myanmar while that of the South (NB) is derived from Sumatra region as it has been proposed earlier (Elwes 1873; Balakrishnan and Ellis 1996). The mid part woody flora might have evolved as a result of confluence of these two regions. However, the long physical gap (100 gap ocean) above the Car-Nicobar Islands may have restricted a complete merger of the vegetation over time.

A strong association of certain families with the three clusters (Fig. 6 and see Additional file 1: Figure S9) also supports the taxonomic and evolutionary distinctiveness of three identified Phyto-regions within Andaman and Nicobar Islands. Thus, it is likely that the spatial assembly, taxonomic and evolutionary diversity of woody flora in Andaman and Nicobar Islands may be better explained by multiple factors.

Though, previous studies have made an effort to document the richness and diversity of woody flora in Andaman and Nicobar Islands, they are all restricted locally to either part of Andaman or Nicobar Islands (Lal 1990; Elkunchwar et al. 1997; Padalia et al. 2004; Tripathi et al. 1994; Rajkumar and Parthasarathy 2008; Prasad et al. 2009). However, our study represents the first effort to document the spatial distribution pattern of richness and diversity of woody flora across entire Andaman and Nicobar Islands by documenting distribution and abundance of woody flora at very fine scale following grid sampling method (841 grids of size 3.18 $\mathrm{km} \times 3.18 \mathrm{~km})$. Moreover, our study also for the first time estimated the spatial pattern of woody plant phylogenic diversity in the region. Woody plants represent the important distinguishing feature of vegetation types in Andaman and Nicobar Islands. They are well represented by both angiosperm and gymnosperm plant families and occur across a diverse range of habitat types including Mangrove forest and Littoral forest.

\section{Conclusion}

Overall, our study highlights that woody plants in Andaman and Nicobar Islands can be grouped into three distinct 'phytoregions' based upon their taxonomic and evolutionary affinities and allows for the development of hypotheses about the origins and evolutionary histories of the woody flora within these Islands. In addition, the spatial pattern of taxonomic richness and diversity and phylogenetic diversity reveal taxonomic and evolutionary diversity hotspots of woody flora within these Islands and have major implication for biodiversity conservation in the region. Our study thus reveals how fine scale spatial distribution data of species, integrated with their phylogenetic analysis can provide new insights into the spatial structure of biodiversity and reveal hidden evolutionary history of vegetation in the region.

\section{Additional file}

Additional file 1: Spatial distribution of taxonomic and phylogenetic diversity of woody flora in Andaman and Nicobar Islands. (DOC $3921 \mathrm{~kb}$ )

\section{Abbreviations}

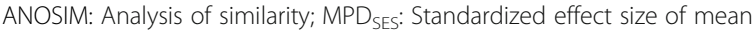
pairwise phylogenetic distance; NMDS: Non-metric multidimensional scaling; PD SEs: Standardized effect size of Faith's phylogenetic diversity;

$\mathrm{p} \beta$ : Phylogenetic component of beta diversity; UPGMA: Unweighted pairgroup method using arithmetic averages; UPGMC: Unweighted pair-group method using centroids; WPGMA: Weighted pair-group method using arithmetic averages; WPGMC: Weighted pair-group method using centroids; $\beta$ sim: Simpson beta diversity; $\beta$ sor: Sørensen beta diversity

\section{Acknowledgements}

We acknowledge the help of Department of Forestry, Andaman and Nicobar Islands, The Social Welfare department and the Regional Unit of Botanical Survey of India, Port Blair. Indian Navy also helped us in transporting the teams to far off islands during the study.

\section{Authors' contributions}

The entire work was conceived by KNG, the work was executed by MS in North Andamans, by RR in Mid Andaman, by CM in Nicobar Islands and by KNG in South Andamans; KNS did the analysis with the help of KNG. First draft of MS was written by KNS with KNG; later all authors worked on it. All authors read and approved the final manuscript.

\section{Authors' information}

KNG works in the School of Ecology and Conservation, UAS GKVK Bangalore, India; He is superannuated as professor and Dean (post graduate studies), UAS GKVK Bangalore, India. He is specialized in Biodiversity and

Ecoinformatics and coordinated the major projects related to Mapping and digital inventory of bioresurces of India. SM is an INSA Senior Scientist in Mahatma Gandhi Botanical Garden, University of Agricultural Sciences, Bangalore, India. He is basically a plant taxonomist specialized on Indian Flora. RR is a professor in Biodiversity Conservation Division in Department of Botany, Sri Krishnadevaraya University, Ananthpur, India. He is mainly specialized in plant taxonomy and biodiversity conservation. CM is a senior scientist in Botanical Survey of India (BSI), Andaman and Nicobar Islands, India. He has mainly specialized in plant taxonomy and biodiversity conservation. KNS is a bridging post-doctoral research fellow in Ashoka Trust for Research in Ecology and Environment (ATREE), Bangalore, India. He is currently working on evolution of reproductive traits in angiosperms and historical biogeography and macroecological pattern of Indian flora.

\section{Funding}

This work is an outcome of the DBT sponsored project on 'Quantitative assessment and mapping of plant resources of Andaman and Nicobar Islands', sponsored by the Department of Biotechnology, Government of India, New Delhi and coordinated by KNG. 


\section{Availability of data and materials}

After acceptance data will be made publicly available as an additional supporting file.

\section{Ethics approval and consent to participate}

Not applicable.

\section{Consent for publication}

Not applicable.

\section{Competing interests}

The authors declare that they have no competing interests.

\section{Author details}

${ }^{1}$ School of Ecology and Conservation, University of Agricultural Sciences, Bengaluru 560065, India. ${ }^{2}$ Mahatma Gandhi Botanical Garden, University of Agricultural Sciences, Bengaluru 560065, India. ${ }^{3}$ Department of Botany, Sri Krishna Devaraya University, Ananthapur, India. ${ }^{4}$ Botanical Survey of India (BSI), Coimbatore, Tamilnadu 641003, India. ${ }^{5}$ The Nature Conservancy Center, 37, Link Road, Lajpatnagar, New Delhi, Delhi 110024, India. 'Suri Sehgal Centre for Biodiversity and Conservation, Ashoka Trust for Research in Ecology and the Environment, Royal Enclave, Sriramapura, Jakkur Post, Bangalore, Karnataka 560064, India.

Received: 14 March 2019 Accepted: 10 July 2019

Published online: 05 August 2019

\section{References}

Abdulali H (1981) Additional notes on Andaman birds. J Bombay Nat Hist Soc 78:46-49 Abdulali H, Grubh R (1970) A new race of the Blackcrested Baza Aviceda leuphotes (Dumont), from the Andaman Islands. J Bombay Nat Hist Soc 67:137-138

Abrahamczyk S, de Vos JM, Sedivy C, Gottleuber P, Kessler M (2014) A humped latitudinal phylogenetic diversity pattern of orchid bees (Hymenoptera: Apidae: Euglossini) in western Amazonia: assessing the influence of climate and geologic history. Ecography 37(5):500-508

Ali S, Ripley SD (1968-1974) Handbook of the birds of India and Pakistan, vol 10. Oxford University Press, New Delhi

Ali S, Ripley SD (1983) Handbook of the birds of India and Pakistan, Compact edn. Oxford University Press, New Delhi

Arisdason W, Lakshminarasimhan P (2013) An outline of plant diversity in the Andaman and Nicobar Islands. http://www.bsienvis.nic.in. Accessed 15 Mar 2019

Balakrishnan NP, Ellis JL (1996) Andaman and Nicobar Islands. Flora of India, Part 1. Botanical Survey of India, Calcutta

Ball V (1873) List of birds known to occur in the Andaman and Nicobar Islands. Stray Feath 1:51-90

Baselga A (2010) Partitioning the turnover and nestedness components of beta diversity. Glob Ecol Biogeogr 19:134-143

Baselga A, Orme CDL (2012) betapart: an R package for the study of beta diversity. Methods Ecol Evol 3:808-812

Blanford, W.T. (1901) The distribution of vertebrate animals in India, Ceylon, and Burma. Phil. Trans. Roy. Soc. B, 194, 201-436.

Brunbjerg AK, Cavender-Bares J, Eiserhardt WL (2014) Multiscale phylogenetic structure in coastal dune plant communities across the globe. J Plant Ecol 7: $101-114$

Champion HG, Seth SK (1968) The revised forest types of India, New Delhi

Charrad M, Ghazzali N, Boiteau V, Niknafs A (2014) NbClust package: finding the relevant number of clusters in a dataset. J Stat Softw 61:1-36

Cook RE (1969) Variation in species density in North American birds. Syst Zool 18: 63-84

Culmsee H, Leuschner C (2013) Consistent patterns of elevational change in tree taxonomic and phylogenetic diversity across Malesian mountain forests. J Biogeogr 40:1997-2010

Cushman JH, Lawton JH, Manly BF (1993) Latitudinal patterns in European ant assemblages: variation in species richness and body size. Oecologia 95(1):30-37

Devaraj P (2001) Forests of Andaman Islands. International Book Distributors, Dehradun

Diamond JM (1970) Ecological consequences of island colonization by Southwest Pacific birds, I. types of niche shifts. Proc Natl Acad Sci U S A 67:529-536
Duchêne DA, Cardillo M (2015) Phylogenetic patterns in the geographic distributions of birds support the tropical conservatism hypothesis. Glob Ecol Biogeogr 24(11):1261-1268

Elkunchwar S, Savant PV, Rai SN (1997) Status of natural regeneration in tropical forests of the Andaman Islands. Indina Forester 123:1091-1106

Ellis $J$ (1987) Oryza indandamanica Ellis, a new species from islands of Andamans. Bull Bot Surv India 27:225-227

Elwes HJ (1873) On the geographical distribution of Asiatic birds. Zool Soc Lond 1873:645-682

Escalante T, Morrone JJ, Rodríguez-Tapia G (2013) Biogeographic regions of north American mammals based on endemism. Biol J Linn Soc 110:485-499

ESRI (Environmental Systems Resource Institute) (2010) ArcMap 10.0, ArcGIS Desktop. ESRI Redlands, California, USA

Forest F, Grenyer R, Rouget M, Davies TJ, Cowling RM, Faith DP, Balmford A, Manning JC, Proches S, van der Bank M, Reeves G, Hedderson TAJ Savolainen V (2007) Preserving the evolutionary potential of floras in biodiversity hotspots. Nature 445:757-760

Fox J, Weisberg S, Bates D, Fox MJ (2012) Package 'car'. R Foundation for Statistical Computing, Vienna http://www.R-project.org/. Accessed 15 Mar 2019

Fritz SA, Rahbek C (2012) Global patterns of amphibian phylogenetic diversity. J Biogeogr 39:1373-1382

Ganeshaiah KN (2012) Plants of Western Ghats. National Bioresource Development Board. Department of Biotechnology, Govt of India, New Delhi

González-Caro S, Umaña MN, Álvarez E, Stevenson PR, Swenson NG (2014) Phylogenetic alpha and beta diversity in tropical tree assemblages along regionalscale environmental gradients in Northwest South America. J Plant Ecol 7:145-153

Graves, G.R. \& Gotelli, N.J. (1983) Neotropical landbridge avifaunas: new approaches to null hypotheses in biogeography. Oikos, 41, 322-333.

Graham CH, Fine PVA (2008) Phylogenetic beta diversity: linking ecological and evolutionary processes across space in time. Ecol Lett 11:1265-1277

Hajra PK, Rao PSN, Mudgal V (1999) Flora of Andaman and Nicobar Islands. Botanical Survey of India

Hawkins BA, Rueda M, Rangel TF, Diniz-Filho JAF (2014) Community phylogenetics at the biogeographical scale: cold tolerance, niche conservatism and the structure of north American forests. J Biogeogr 41:23-38

Heaney LR (1986) Biogeography of mammals in SE Asia: estimates of rates of colonization, extinction, and speciation. Biol J Linn Soc 28:127-165

Heikinheimo H, Fortelius M, Eronen J, Mannila H (2007) Biogeography of European land mammals shows environmentally distinct and spatially coherent clusters. J Biogeogr 34:1053-1064

Holt BG, Lessard JP, Borregaard MK, Fritz SA, Araújo MB, Dimitrov D, Fabre PH, Graham CH, Graves GR, Jønsson KA, Nogués-Bravo D (2012) An update of Wallace's zoogeographic regions of the world. Science 20:1228282

Hubbell SP, Foster RS (1986) Canopy gaps and the dynamics of a neotropical forest. In: Crawley MJ (ed) Plant ecology. Blackwell Scientific Publications, Oxford, pp 77-96

Jønsson KA, Holt BG (2015) Islands contribute disproportionately high amounts of evolutionary diversity in passerine birds. Nat Commun 6:8538

Joseph S, Anitha K, Srivastava V, Reddy CS, Thomas AP, Murthy MSR (2012) Rainfall and elevation influence the local-scale distribution of tree community in the southern region of Western Ghats biodiversity hotspot (India). Int J For Res 2012:1-10

Kembel SW, Cowan PD, Helmus MR, Cornwell WK, Morlon H, Ackerly DD, Blomberg SP, Webb CO (2010) Picante: R tools for integrating phylogenies and ecology. Bioinformatics 26(11):1463-1464

Kreft H, Jetz W (2010) A framework for delineating biogeographical regions based on species distributions. J Biogeogr 37:2029-2053

Krupnick GA, Kress WJ (2003) Hotspots and ecoregions: a test of conservation priorities using taxonomic data. Biodivers Conserv 12:2237-2253

Kurz (1870) Report on vegetation of the Andaman Islands. Govt Printing, Calcutta

Lal R (1990) Diversity and distributional pattern of trees in the tropical rainforest in South Andamans. M.S. Thesis, Univ Pondicherry, India, p 78

Lennon JJ, Koleff P, Greenwood JJD, Gaston KJ (2001) The geographical structure of British bird distributions: diversity, spatial turnover and scale. J Anim Ecol 70:966-979

Leprieur F, Albouy C, De Bortoli J, Cowman PF, Bellwood DR, Mouillot D (2012) Quantifying phylogenetic beta diversity: distinguishing between "true" turnover of lineages and phylogenetic diversity gradients. PLoS One 7:e42760

Maechler M, Rousseeuw P, Struyf A, Hubert M, Hornik K (2013) cluster: cluster analysis basics and extensions. In: R package version 1.14.4 http://www2. uaem.mx/r-mirror/web/packages/cluster/citation.html. Accessed 15 Mar 2019 
Mani MS (1974) Ecology and biogeography in India. Junk, The Hague

Mayr E, Diamond JM (1976) Birds on islands in the sky: origin of the montane avifauna of northern Melanesia. Proc Natl Acad Sci U S A 73:1765-1769

Meyer D, Zeileis A, Hornik K, Gerber F, Friendly M (2014) Package 'vcd'. http:// cran.r-project.org/web/packages/vcd/vcd.pdf. Accessed 20 Jan 2018

Milligan GW, Cooper MC (1985) An examination of procedures for determining the number of clusters in a data set. Psychometrika 50:159-179

Morinière J, van Dam MH, Hawlitschek O, Bergsten J, Michat MC, Hendrich L, Ribera I, Toussaint EF, Balke M (2016) Phylogenetic niche conservatism explains an inverse latitudinal diversity gradient in freshwater arthropods. Sci Rep 6:26340

Murali KS, Kavitha A, Harish RP (2003) Spatial patterns of tree and shrub species diversity in Savanadurga state Forest, Karnataka. Curr Sci 84:808-813

Nayar MP (1996) Hot spot of endemic plants of India, Nepal and Bhutan. Tropical Botanic Garden and Research Institute, Thiruvanthapuram

Oates EW, Blanford WT (1889-1898) The fauna of British India, birds, vol 4, 1st edn. Taylor and Francis, London

Oksanen J, Blanchet FG, Kindt R, Legendre P, Minchin PR, O'Hara RB, Simpson GL, Solymos P, Stevens MHH, Wagner H (2015) Vegan: community ecology package. In: R package version 2.3-0 http://CRAN.R-project.org/package= vegan. Accessed 15 Mar 2019

Owen DF, Owen J (1974) Species diversity in temperate and tropical Ichneumonidae. Nature 249:583-584

Padalia H, Chauhan N, Porwal MC, Roy PS (2004) Phytosociological observations on tree species diversity of Andaman Islands. Ind Curr Sci 87(6):799-806

Padalia H, Roy PS (2010) Tropical rain forest mapping and community analysis of south Andaman Islands (India). J Indian Soc Remote 38(3):549-563

Paradis E, Claude J, Strimmer K (2004) APE: analyses of phylogenetics and evolution in R language. Bioinformatics 20:289-290

Parkinson CE (1923) A forest flora of the Andaman Islands. Government Central Press, Simla

Prasad PR, Sringeswara AN, Reddy CS, Nagabhatla N, Rajan KS, Giriraj A, Murthy MS, Raza SH, Dutt CB (2009) Assessment of forest fragmentation and species diversity in north Andaman Islands (India): a geospatial approach. Int J Ecol Dev 14(F09):33-46

Prasad RCP, Reddy CS, Dutt CBS (2007) Phytodiversity assessment of tropical rainforest of north Andaman Islands, India. Res J For 1:27-39

Pyron RA, Burbrink FT (2009) Can the tropical conservatism hypothesis explain temperate species richness patterns? An inverse latitudinal biodiversity gradient in the New World snake tribe Lampropeltini. Glob Ecol Biogeogr 18(4):406-415

R Core Team (2013) R: A Language and Environment for Statistical Computing. R Foundation for Statistical Computing, Vienna. http://www.Rproject.org/.

Rajkumar M, Parthasarathy N (2008) Tree diversity and structure of Andaman Giant Evergreen Forests, India. Taiwania 53(4):356-368

Ramesh BR, Venugopal PD, Pélissier R, Patil SV, Swaminath MH, Couteron P (2010) Mesoscale patterns in the floristic composition of forests in the Central Western Ghats of Karnataka, India. Biotropica 42(4):435-443

Revell LJ (2012) Phytools: phylogenetic tools for comparative biology (and other things). Methods Ecol Evol 3(2):217-223

Ricklefs RE (2004) A comprehensive framework for global patterns in biodiversity. Ecol Lett 7(1):1-15

Ricklefs RE, Schluter D (1993) Species diversity: regional and historical influences. In: Ricklefs RE, Schluter D (eds) Species diversity in ecological communities: historical and geographical perspectives. Univ of Chicago Press, pp 350-359

Ripley SD, Beehler BM (1989) Ornithogeographic affinities of the Andaman and Nicobar Islands. J Biogeogr 16:323-332

Rivadeneira MM, Thiel M, González ER, Haye PA (2011) An inverse latitudinal gradient of diversity of peracarid crustaceans along the Pacific coast of South America: out of the deep south. Glob Ecol Biogeogr 20(3):437-448

Santelices, B., 1980. Phytogeographic characterization of the temperate coast of Pacific South America. Phycologia 19: 1-12.

Sinha BK, Hajra PK, Rao PSN (1999) Flora of great Nicobar Island. Botanical Survey of India, Calcutta

Sokal RR, Rohlf FJ (1962) The comparison of dendrograms by objective methods. Taxon 11:33-40

Thothathri K (1965) Pubistylus Thoth. -an interesting new genus of Rubiaceae from Andaman Islands. Reinwardtia 7:283-286

Tikader BK (1984) Birds of the Andaman and Nicobar Islands. Zoological Survey of India, Calcutta
Tripathi KP, Tripathi S, Selven T, Kumar K, Singh KK, Mehrotra S, Pushpangadan P (1994) Community structure and species diversity of saddle peak forests in Andman Island. Trop Ecol 45(2):241-250

Tsirogiannis C, Sandel B (2016) PhyloMeasures: a package for computing phylogenetic biodiversity measures and their statistical moments. Ecography 39:709-714

Valdovinos C, Navarrete SA, Marquet PA (2003) Mollusk species diversity in the southeastern Pacific: why are there more species towards the pole? Ecography 26:139-144

Wallace, A. R. 1876. The geographical distribution of animals; with a study of the relations of living and extinct faunas as elucidating the past changes of the Earth's surface. New York: Harper \& Brothers. 2.

Wei T, Simko V (2017) R package "corrplot": Visualization of a Correlation Matrix (Version 0.84). https://github.com/taiyun/corrplot. Accessed 20 Jan 2018

Wikramanayake ED, Dinerstein E, Loucks CJ, Olson DM, Morrison J, Lamoreux J, McKnight M, Hedao P (2002) Terrestrial ecoregions of the indo-Pacific: a conservation assessment. Island Press, Washington, DC

Zanne AE, Tank DC, Cornwell WK, Eastman JM, Smith SA, FitzJohn RG, McGlinn DJ, O'Meara BC, Moles AT, Reich PB, Royer DL, Soltis DE, Stevens PF, Westoby M, Wright IJ, Aarssen L, Bertin RI, Calaminus A, Govaerts R, Hemmings F, Leishman MR, Oleksyn J, Soltis PS, Swenson NG, Warman L, Beaulieu JM (2014) Three keys to the radiation of angiosperms into freezing environments. Nature 506:89-92

\section{Submit your manuscript to a SpringerOpen ${ }^{\circ}$ journal and benefit from:}

- Convenient online submission

- Rigorous peer review

- Open access: articles freely available online

- High visibility within the field

- Retaining the copyright to your article

Submit your next manuscript at $\boldsymbol{\nabla}$ springeropen.com 